\title{
高速触覚システムを用いたペン状物体の高速把持・操り
}

\section{High-speed grasp and manipulation of a pen-shaped object using a high-speed multifingered hand with high-speed tactile sensor}

\author{
○学石原達也（東大）正 並木 明夫（東大） 正 石川正俊（東大） 正 下条誠（電通大） \\ Masatoshi ISHIKAWA, Univ. of Tokyo, Hongou 7-3-1, Bunkyou-ku, Tokyo \\ Akio NAMIKI, JST / Univ. of Tokyo \\ Makoto Shimojo, Univ. of Electro-Communications, Chohugaoka 1-5-1, Chohu, Tokyo \\ Tatsuya Ishihara, Univ. of Tokyo
}

Key Words: tactile feedback, robot hand, pen spinning

\begin{abstract}
We propose a tactile feedback system in real time using a high-speed multifingered robot hand and high-speed tactile sensor. The hand and the sensor is respectively capable of high-speed finger motion up to 180 deg per $0.1 \mathrm{~s}$ and high-speed tactile feedback with a sampling rate higher than $1 \mathrm{kHz}$. We have achieved the pen spinning task using the two robot fingers. In this paper, we describe dynamic pen spinning as an example of a skillful manipulation task with the three robot fingers using the system. The paper describes the tactile feedback control strategies and experimental results.
\end{abstract}

1. はじめに

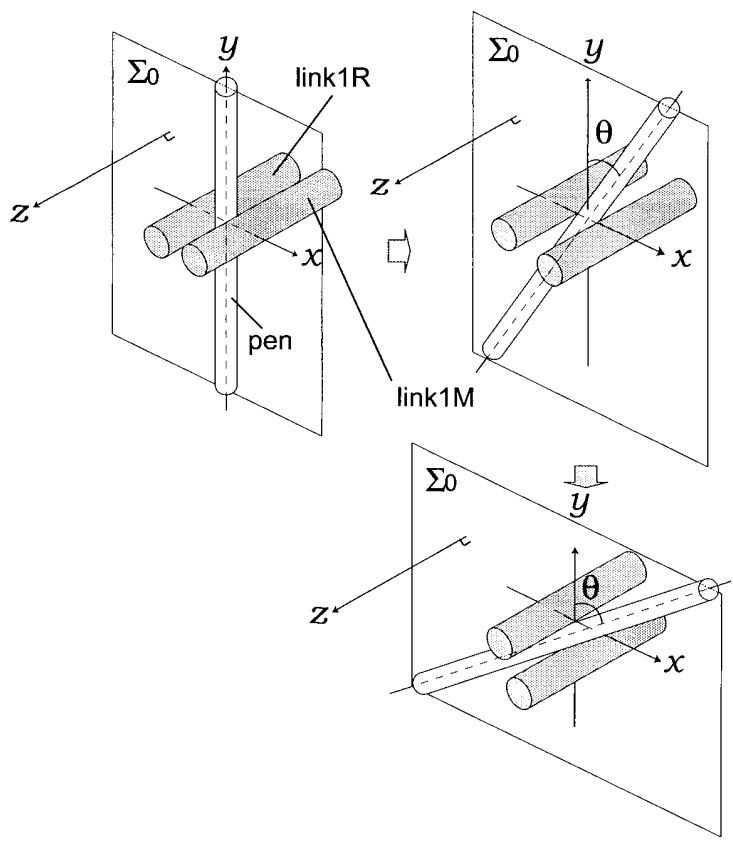

Fig. 1.1 Model of the pen spinning.

我々は、視覚とロボットハンドとの感覚統合によって、人間 や従来あるロボットをはるかに超える超高速・高機能ロボット ハンドシステムを構築した。また、それによって様々な高速動 作を要する夕スク 1)2)3) を実現させてきた。高速動作の必要性 としては、例えば産業界において効率化を可能ならしめるこ とや、ロボットが外界変化に対応して瞬時に判断・行動するこ とが可能となることなどが挙げられる。

しかし、より器用な操作を追求するためにはロボットハンド に細かな接触操作が要求される。そこで触覚が重要な役割を 果たすが、現状では、触覚フィードバック 4)5)6)を高速作業に 適応した例は少ない。

現在、高速ロボットハンドのサンプリングタイムが $1[\mathrm{~ms}]$ 程
度であることを考えると、触覚センサの応答性がこれよりも 速いことが望まれる。これによって、シンプルかつ効果的なシ ステムを構築することが可能となる。我々は電通大の下条研で 開発された高速触覚センサ7)使用することにより新たなる夕 スクの実現を目指す。

本稿では以上の点を踏まえて、高速動作に因らなければで きない器用なタスクの一例として、三指高速ロボットハンド でペン状物体を落とすことなく高速回転させることを目指す （図 1.1）。これは、手の対象物体としてペン状物体が多いから である。以下にタスク実現への一過程として、まず、二本指で のペン振り動作を実現させるための戦略とアルゴリズムを示 す。その後に応用として三本指でのペン回し動作の実現におけ る戦略と結果を示す。

\section{2. 高速ハンドと触覚センサ}

三本指軽量高速ロボットハンドの外観を、図 2.1 に示す。こ のロボットハンドは $1[\mathrm{~ms}]$ のサンプリングレートを持ち、0.1[s] 間に $180[\mathrm{deg}]$ の高速動作が可能である。ロボットハンド各関 節角度は下方向を正とする（図 2.2）。

また、触覚センサの外観、内部構造をそれぞれ図 2.3 に示す。 この触覚センサは、 $1[\mathrm{~ms}]$ 以内の応答性を持ち、負荷の値と 2 次元負荷重心の位置 $(X, Y)$ を計測でき、今回はロボットハン ド各指の link1に取り付けられている。

3. 二本指ペン振り動作実現への戦略とアルゴリズム ペン状物体の長軸方向と鉛直軸との角度 $\theta$ (図 1.1) が望まし い軌道を描くようにロボットの各関節軌道を動かす。本章では、 幾何学的な各関節角目標軌道式導出に加えて、触覚フィード バックにより各関節軌道を修正していく手法について述べる。

3-1 目標軌道 ペン状物体を回転させるにあたつて以下の仮 定をおく。

(i) ペン状物体は、 $(x, y)$ で表される二次元平面 $\left(\Sigma_{0}\right)$ 上を運 動する（図 3.1）。

(ii)link1Rの中心点は $x$ 軸上を、link1M の中心点は $y$ 軸上を それぞれ動く。 


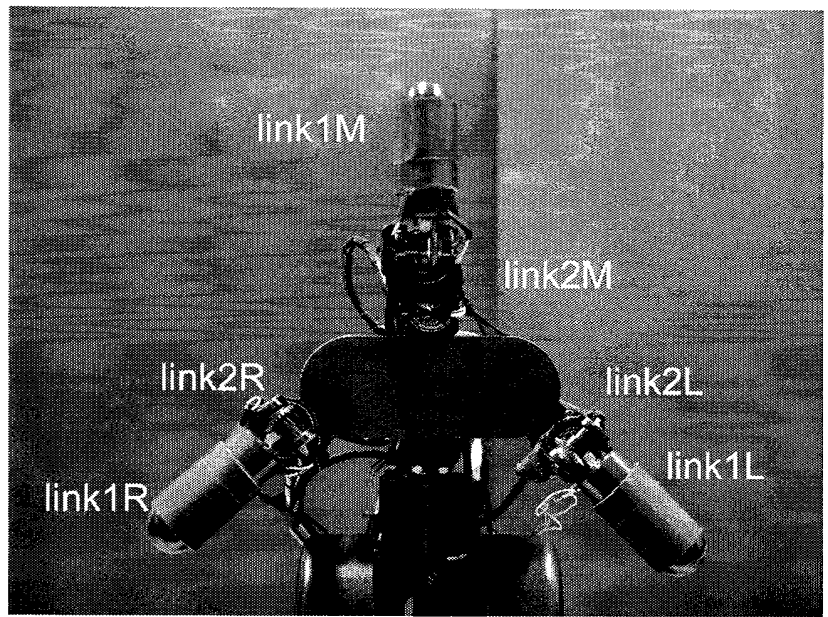

link 1

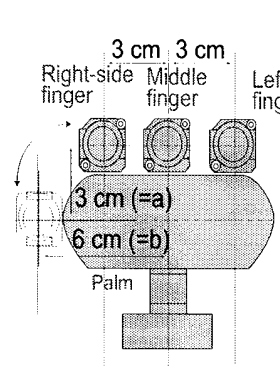

(a) Front view

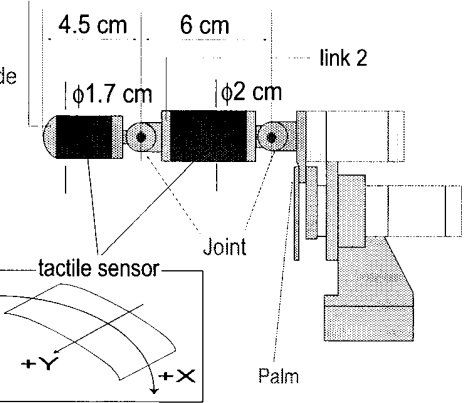

(b) Left view

Fig. 2.1 Photo and model of High-speed multifingered hand with tactile sensors..

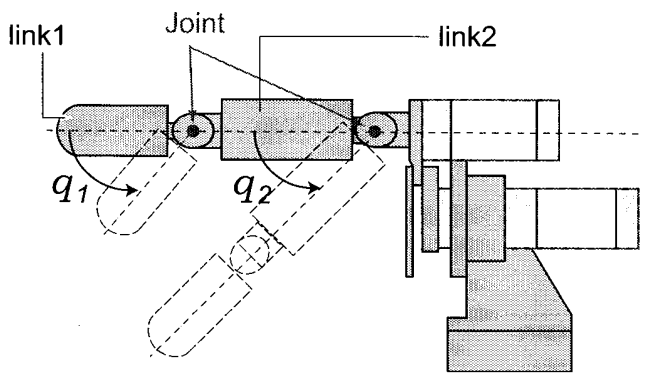

Fig. 2.2 Angle of the robotic finger.

以上の仮定により、ロボットハンドの各関節角目標軌道 $q$ が 以下のように表せる。

$$
\begin{aligned}
& q_{1 M}=-q_{2 M}, \quad q_{1 R}=-q_{2 R} \\
& q_{1 M}=\sin ^{-1}\left\{\frac{2(r+l) \sin \theta-2 d \cos \theta+a}{b}\right\} \\
& q_{1 R}=\sin ^{-1}\left\{\frac{-2(r+l) \cos \theta-2 d \sin \theta+b}{b}\right\}
\end{aligned}
$$

ここで、添え字はそれぞれ図 2.1 に対応させる。

また、ペン状物体とハンドとの間で滑りがないと仮定する と以下の式が得られる。

$$
d=r \theta+d_{0}
$$

ここで、 $d_{0}$ は初期状態によって定まる定数である。

3-2 触覚フィードバック ハンドにペン状物体を回転させる 際、初期状態や物体の大きさの違い等により、各関節角度に

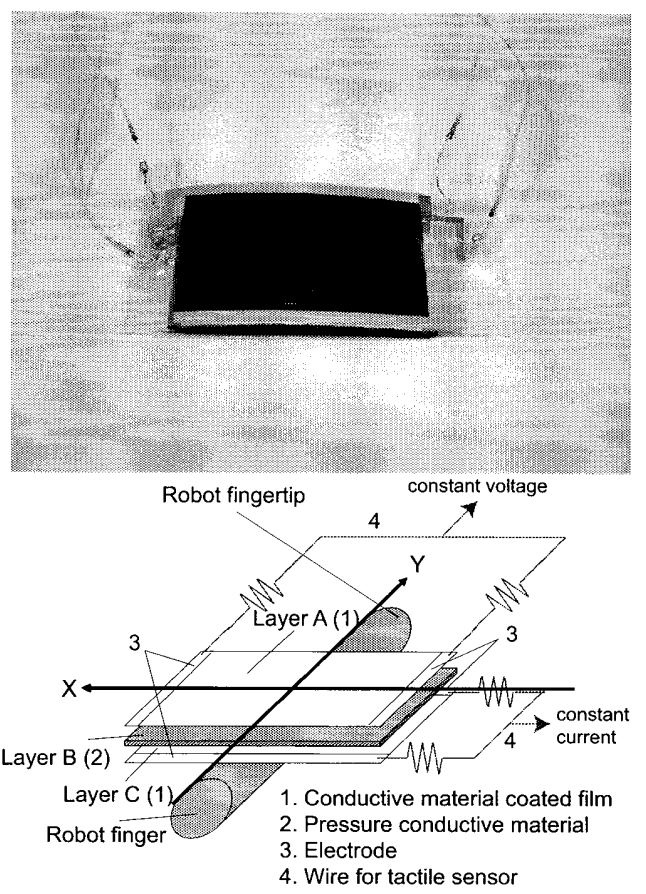

Fig. 2.3 Photo and structure of tactile sensor.

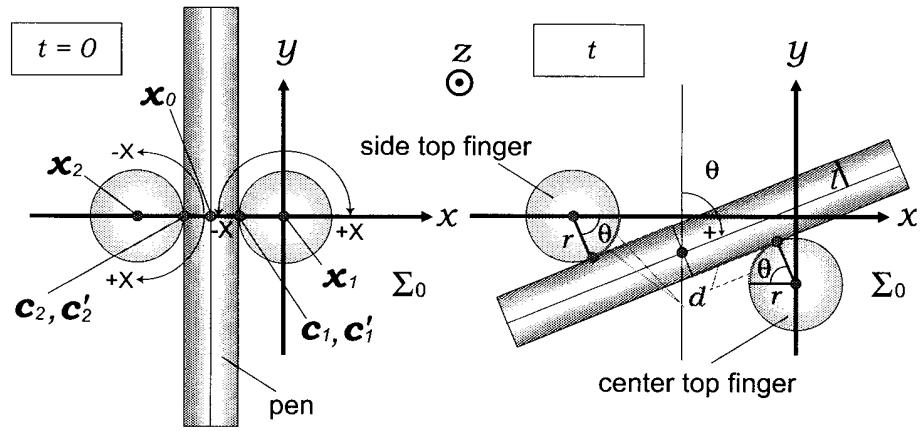

Fig. 3.1 Approximated model of front view.

目標軌道を与えるだけでは成功しない。そこで中指の各関節 を目標軌道に沿わせながら、以下に述べる触覚センサによる フィードバックを用いて両サイドの指の各関節軌道を補う。

3-2-1 カフィードバック 触覚センサにより得られる力の值 $f$ によって、link2R の軌道を修正する。以下の式により、修正 目標軌道 $q_{2 R}^{\prime}$ を得る。

$$
q_{R 2}^{\prime}=q_{R 2}+K J(\theta) \int(F-f) \cdot d t
$$

ここで、 $K, J(\theta), F$ はそ执ぞれ、比例ゲイン、適当なスカラー、 そして力の目標值である。

3-2-2 位置フィードバック 触覚センサにより得られる位置 情報 $Y$ によって、link1R の軌道を修正する。ここでは、触覚 センサによって訃測される $Y$ 軸方向の值が一定の範囲内に収 まるように link1R の関節角度を微小に変化させる（図 3.2 参 照)。以下の式により、修正目標軌道 $q_{1 R}^{\prime}$ を得る。

$$
q_{1 R}^{\prime}=q_{1 R}+\delta
$$

ここで $\delta$ は微小変位である。 


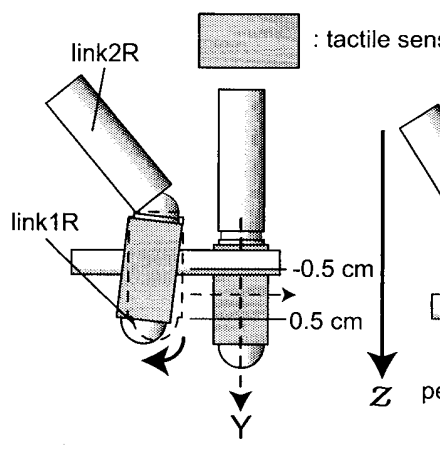

(a) $Y<-0.5$

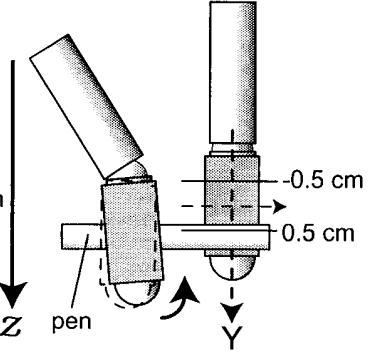

(a) $Y>0.5$
Fig. 3.2 Control model of the side top finger.
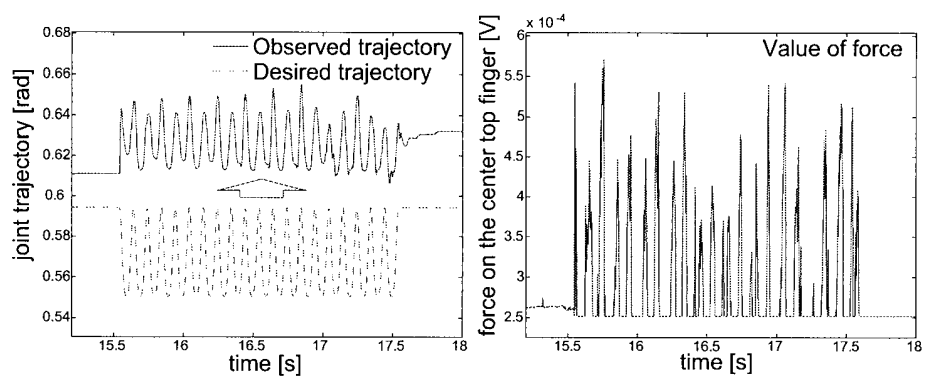

Fig. 4.1 Trajectory of side root finger with force feedback.

\section{4. 実験結果}

今回ペン状物体として、直径 $1.7[\mathrm{~cm}]$ 、長さ $35[\mathrm{~cm}]$ 、重さ $2[\mathrm{~g}]$ の円柱を使用した。また、回転速度を $5[\mathrm{~Hz}]$ とした。

円柱が以下の軌道で 10 周期ペン振り動作できるように、口 ボットハンドの各関節角度を動かした時の実験結果を以下に 示す。

$$
\theta=\frac{\pi}{3} \sin (10 \pi t)
$$

4-1 カフィードバック 図4.1に、目標軌道と力フィードバッ クによって修正した目標軌道を示す。力フィードバックによる 軌道修正により、物体を落とさないように link2R の関節角度 がより内側に遷移していることが分かる。

4-2 位置フィードバック 図 4.2 により、触覚センサの位置 フィードバックによって物体の $Y$ 軸上での動きが特定の範囲 （-0.5〜0.5）に収まるように制御されていることが分かる。

4-3 考察 図4.3から実際にペンがどのような動きをしたか 観察できる。ここでセンサ上の $X$ の值の振幅が約 $1.5 \mathrm{~cm}$ であ り、式 (4) から実際のペンの振幅は 50.6 度と推定される。ま た、二本指でのペン回振り動作の様子を示した高速写真を困 4.4 に示す。

\section{5. 三本指ペン回し動作実現への戦略と実験結果}

以上のペン振り動作の応用として、以下の 3 ステップを繰り 返すことによってペン回し動作を実現させた。ただし、（）内 は一回目の流れによるものである。

1. 二本指（link1R, link1M）でのペン振り動作によって、ペ ンが水平近くになるまで勢いを与える。

2. $\theta$ の理論值から、片指（link1R）を離して反対側の指 （link1L）で把持するタイミングを逆算する。
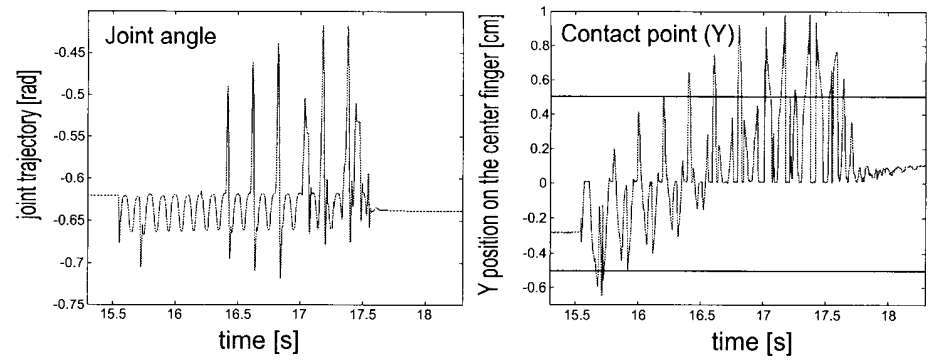

Fig. 4.2 Trajectory of side top finger and Y position.

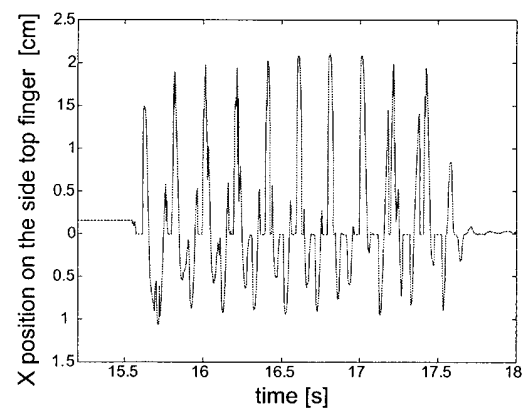

Fig. 4.3 Movement of stick ( $X$ position on the side top finger).

\section{3. 反対側の指にてキャッチ}

今回は $80[\mathrm{deg}]$ になる $30[\mathrm{~ms}]$ 前に、片指を離すと同時に、反 刘側の指でキャッチに移行させた。三本指でのペン回しの様子 を示した $30[\mathrm{~ms}]$ 毎の高速写真を図 5.1 に示す。また、これら の実験結果は $\mathrm{Web}^{8)}$ において動画として見ることができる。

\section{6. まとめ}

高速ロボットハンドと高速触覚センサを用いて、リアル夕 イムでの触覚フィードバックシステムを構築した。また、シス テムの有効性を実証するために高速ペン回し動作を実現した。 今後の展望としては、視覚情報も取り入机た高速視触覚シス テムによってょり高度な高速把持・操り動作の実現を目指す。

\section{参考文献}

1)妹尾, 並木, 石川. High-Speed Batting Using a Multi-Jointed Manipulator. IEEE Int. Conf. Robot. and Automat, pp. 1191-1196, 2004.

2) 今井, 並木, 橋本, 石川. Dynamic active catching using a high-speed multifingered hand and a high-speed vision system. Proc. IEEE Int. Conf. Robot. and Automat., Vo. 2004, No. 2, pp. 1849-1854, 2004.

3) 塩形, 並木, 石川. Robot Dribbling Using a High-Speed Multifingered Hand and a High-Speed Vision System. Proc. IEEE Int. Conf. Intelligent Robots and Systems, pp. 3945-3950, 2005.

4) 前川, 谷江, 小森谷. Tactile Feedback for Multifingered Dynamic Grasping. IEEE Control Systems Magazine, Vol. 17, No. 1, pp. 63$72,1997$.

5) 大隅, 石井, 高橋, 梅田, 木下. Optimal Grasping for a Parallel TwoFingered Hand with Compliant Tactile Sensors. Proc, IEEE Int. Conf. Intelligent Robots and Systems, pages 799-804, 1999.

6) J. S. Son and R. D. Howe. Tactile Sensing and Control with Multifingered Hands. Proc. IEEE Int. Conf. Robot. and Automat., Vo. 4 , pp. 3228-3233, 1996.

7) 下条, 谷保, 並木, 石川. 2 次元分布加重測定法を用いた触覚セン サへの応用. 第 5 回システムインテグレーション部門学術講演 会,pp. 1144-1145, 2004.

8) http://www.k2.t.u-tokyo.ac.jp/fusion/PenSpinning/ 


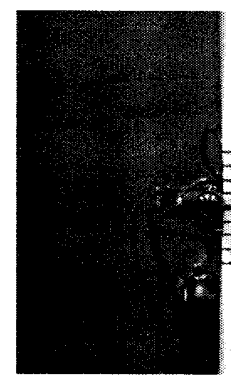

$0[\mathrm{~ms}]$

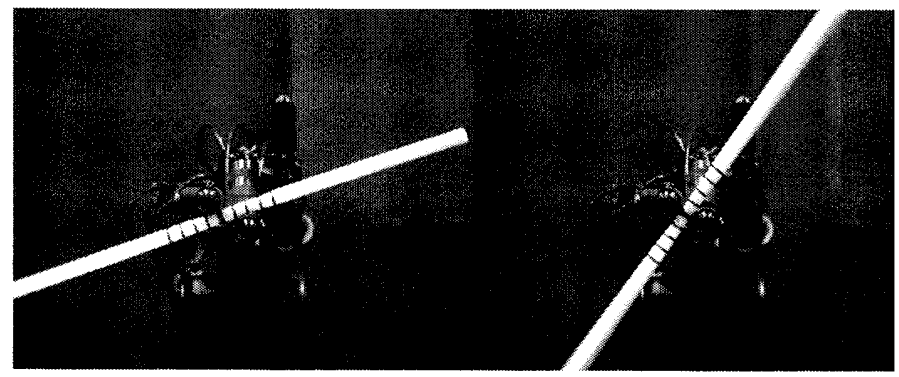

$48[\mathrm{~ms}]$

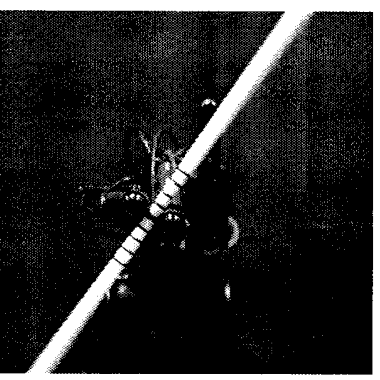

$20[\mathrm{~ms}]$

$72[\mathrm{~ms}]$

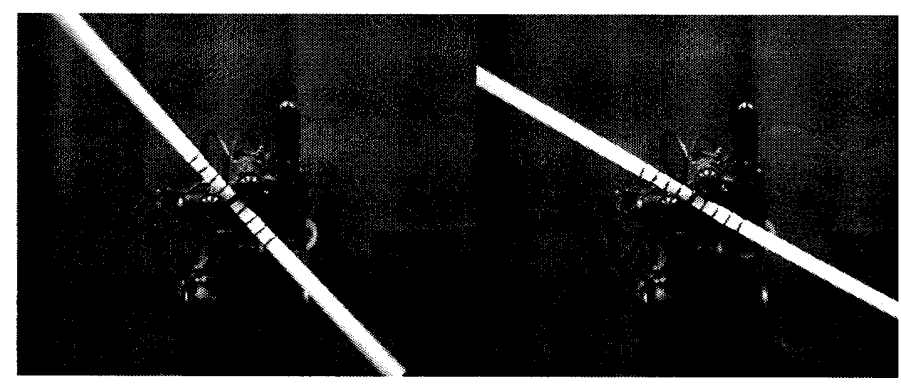

$132[\mathrm{~ms}]$

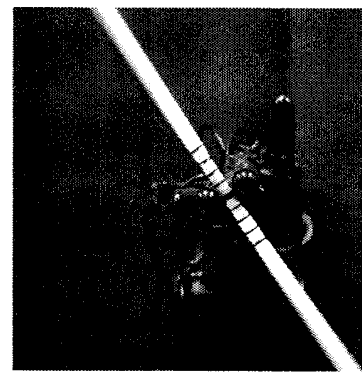

184 [ms]
156 [ms]

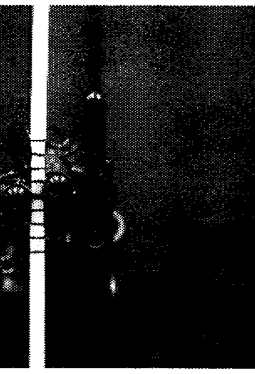

204 [ms]

Fig. 4.4 Continuous sequence of pictures (with two robot fingers).
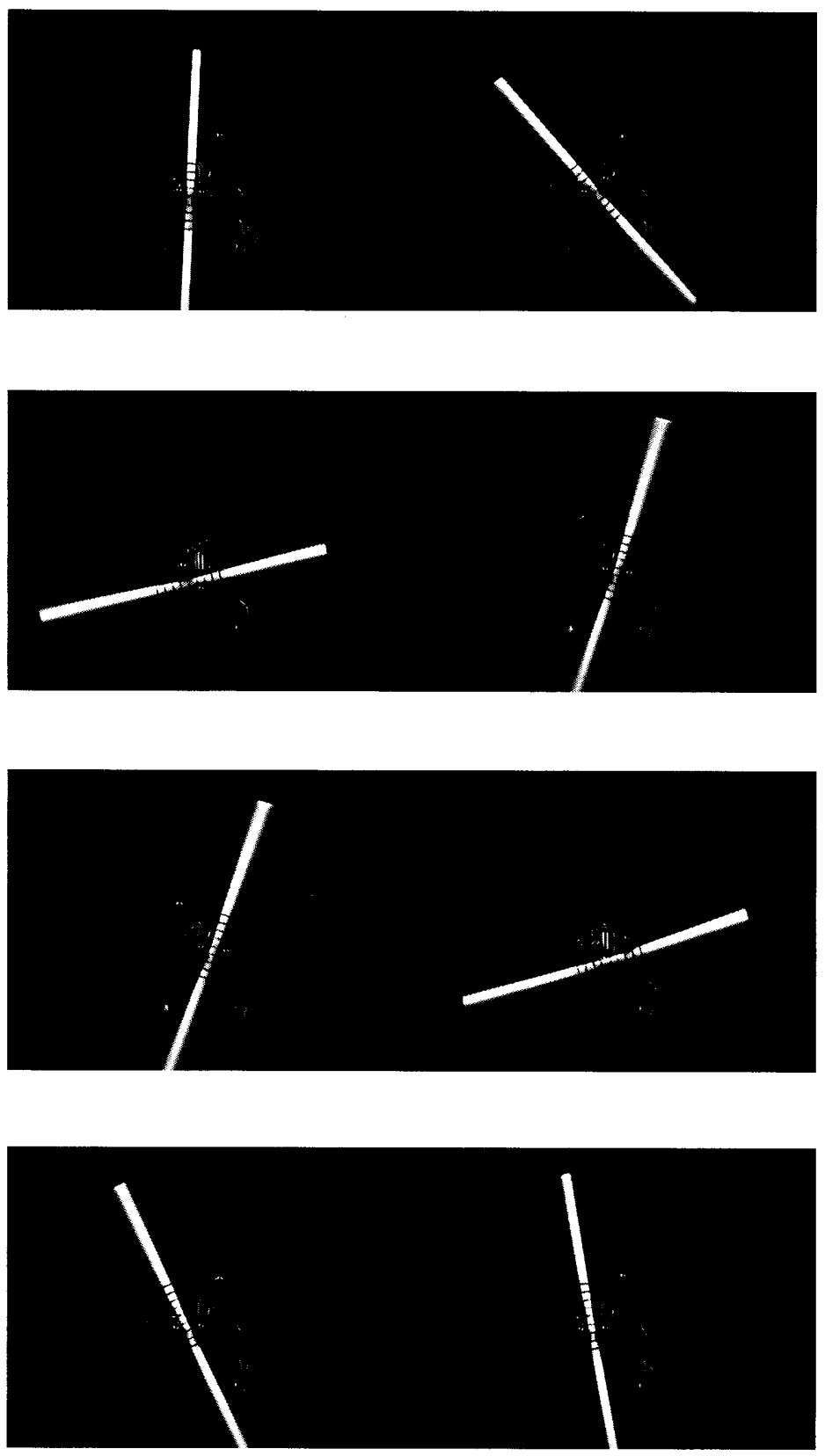

Fig. 5.1 Continuous sequence of pictures (with three robot fingers). 